\title{
The effect of surface irregularities on a falling rock motion
}

\author{
Ivan Gratchev $^{1 *}$, Somayeh Saeidi ${ }^{2}$ \\ 1) Senior Lecturer, Griffith School of Engineering, Griffith University, Parklands Drive, \\ Southport, QLD, 4222, Australia. \\ *Corresponding author. Email: ivangratchev@gmail.com \\ Tel: +61 $755527686 \quad$ Fax: +61 755528065 \\ 2) PhD candidate, Griffith School of Engineering, Griffith University, Australia
}

\begin{abstract}
This laboratory study seeks to investigate the effect of surface irregularities on the motion characteristics of a falling rock. The irregularly-shaped surfaces of greywacke with a range of joint roughness coefficient (JRC) from 2 to 18 were used in an experimental setup where a falling rock was dropped from a height of $110 \mathrm{~cm}$. A high-speed camera was utilized to capture the trajectory of the falling rock upon its impact with the rock surface. The data from 287 tests were statistically analysed to determine the dominant type of motion and to establish relationships between JRC and the coefficient of restitution (CoR). The effect of surface roughness was seen in different modes of motion of the falling rock with more irregular surfaces often produced "sliding” or "rolling” instead of "bouncing”. The obtained data indicated that the rock surface roughness did not seem to have a significant effect on CoR; however, it affected the rebound angle of the falling rock.
\end{abstract}

Key words: laboratory test; coefficient of restitution; joint roughness coefficient, rebound angle 


\section{Introduction}

Rock falls are a natural hazard that causes serious damage to residential areas and infrastructure. When rock falls occur, different types of movement such as free fall, bouncing, sliding and/or rolling (Ritchie 1963) can be expected. As the rock bouncing seems to be the most challenging and least-understood type (Labiouse and Heidenreich 2009), there has been a good deal of research conducted in past decades to better understand the mechanism of this process. The available studies revealed that the trajectory of a bouncing rock as well as the energy dissipation upon the impact of this rock with a rock surface could be estimated by a single parameter called the coefficient of restitution (CoR). It was shown that CoR can be obtained for any type of rock through either field experiments (Giani et al. 2004, Dorren et al. 2006, Asteriou et al. 2012, Spadari et al. 2012, Kim et al. 2015) or laboratory tests (Labiouse and Heidenreich 2009, Buzzi et al. 2012, Chau et al. 2002, Asteriou and Tsiambaos 2016). The literature also indicated that CoR depends on several variables including the geology of rocks (Pfeiffer and Bowen, 1989; Chau et al., 2002), the shape and weight of falling rocks (Labiouse and Heidenreich 2009, Chau et al. 2002, Buzzi et al. 2012, Asteriou et al. 2012), and the inclination of the rock surface (Chau et al. 2002, Labiouse and Heidenreich 2009, Asteriou et al. 2012). Yet, only limited research on the effect of rock surface roughness on CoR has been conducted to date. Wu (1985) carried out a numerical analysis and reported that the surface irregularities could result in the variation of the block trajectory and generate random modes of motion. Giani et al. (2004) noted that local variations of the slope roughness and waviness can introduce significant changes to the paths of falling rocks; however, this effect is difficult to quantify. Wang and Lee (2010) performed a computer analysis of rock falls and noted that a more irregular surface can lead to rolling or sliding instead of bouncing. However, there is still no experimental evidence that 
can support these statements as most of the previous studies were performed on a flat rock surface without considering the effect of surface roughness. Only recently, Buzzi et al. (2012) presented the results of lab tests indicating that the presence of a single "step" (or irregularity) on a flat rock surface can actually affect the trajectory of falling rocks and increase the normal coefficient of restitution. Considering this, it is logical to assume that, compared to a flat surface, a relatively rough rock surface would have a greater impact on the bounce characteristics of a falling rock due to the presence of irregularities.

This study aims at better understanding of the effect of rock surface irregularities on the motion characteristics of a falling rock. A series of laboratory tests were performed in which a rock was dropped on a surface with various degrees of roughness. The roughness of each surface was estimated using a joint roughness coefficient (JRC), with higher JRC values related to more irregular surfaces. The data from 287 tests were statistically analysed to establish whether relationships between JRC and CoR exist. This technical note presents and discusses the obtained results.

\section{Experimental program}

The experimental setup consisted of an irregularly-shaped rock surface, a falling rock, and a high-speed camera (Fig. 1). Two real rocks, which were greywacke from the Brisbane area, Australia (Kim et al. 2015b), were used as rock surfaces S1 and S2 (Fig. 2), respectively. To keep the rock surface stationary upon impact with the falling rock, each surface was embedded in a plaster mould $(40 \times 30 \times 15 \mathrm{~cm})$. The surface of the rock was divided into a grid pattern with a distance of $1 \mathrm{~cm}$ between the adjacent lines while the irregularity of each line was assessed using a joint roughness coefficient (JRC) by means of a Barton's comb (Barton and Choubey 1977). Figure 3 gives an example of JRC values obtained for S1 (Fig. 3a) and S2 (Fig. 3b). It is noted that S1 had a more irregular roughness profile resulting in higher 
values of JRC (12 to 18), compared to S2 whose JRC values ranged from 4 to 12 . To study the effect of surface inclination, the rock surface was inclined at different angels of $0^{\circ}, 20^{\circ}$ and $30^{\circ}$.

A round shaped rock specimen of greywacke (a diameter of $30 \mathrm{~mm}$, a weight of $29.5 \mathrm{~g}$ ) was used as the falling rock. The rock was positioned at the edge of the stand with a height of 110 cm (Fig. 1) and then slightly pushed so that it would fall onto the surface below. The position of the stand varied in each series of tests so that the impact between the falling rock and the surface would occur at different locations. A high-speed camera (200 frames per second) was utilized to record the trajectory of the falling rock. Camera 2 (Fig. 1) was used to determine the impact point of the falling rock with the surface. The footage of each experiment similar to the one shown in Fig. 4a was analysed to calculate the CoR (Eqs. 1-3) using the most commonly adopted definitions (Fig. 4b) in the literature (Giani et al. 2004, Buzzi et al. 2012).

$$
\begin{aligned}
& k_{i}=\frac{v_{i}^{\text {post }}}{v_{i}^{\text {pre }}} \\
& k_{n}=\frac{v_{n}^{\text {post }}}{v_{n}^{\text {pre }}} \\
& k_{t}=\frac{v_{t}^{\text {post }}}{v_{t}^{\text {pre }}}
\end{aligned}
$$

where $\mathrm{k}_{\mathrm{i}}, \mathrm{k}_{\mathrm{n}}$, and $\mathrm{k}_{\mathrm{t}}$ are the kinematic, normal, and tangential restitution coefficients, respectively, $\mathrm{v}_{\mathrm{n}}{ }^{\text {pre }}, \mathrm{v}_{\mathrm{n}}{ }^{\text {post }}$ are the normal components while $\mathrm{v}_{\mathrm{t}}^{\text {pre }}$ and $\mathrm{v}_{\mathrm{t}}{ }^{\text {post }}$ are the tangential components of the block's velocity before and after the impact, respectively.

For each test, the obtained CoR was linked to the JRC of the rock surface where the contact of the falling rock and the rock surface occurred. Although 287 tests were performed, some 
of them did not produce any bouncing, showing only a rolling or sliding behavior. For this reason, the number of results presented is different from the number of tests performed.

\section{Results and discussion}

Type of motion. Figure 5 gives an example of experimental data obtained for a series of tests with S1 inclined at $20^{\circ}$. The symbols in this figure represent the location of impact points and the type of motion. It is noted that although the "bounce" appeared to be the dominant type produced upon the impact of falling rock with the surface, there were several occasions when "sliding” and "rolling” were also observed, especially in the area with more irregular rock surfaces $(\mathrm{JRC}=16-18)$ as shown in Fig. 5. Statistical analysis of all results indicates that $27.2 \%$ tests produced either rolling or sliding modes while for the area of rock surface with higher JRCs (16-18), the total percentage of rock motion other than bouncing was significantly greater, reaching $36.4 \%$.

Restitution coefficients. The average values of CoR were calculated for each series of tests and summarized in Table 1. Figure 6a presents the data in the form of JRC vs the kinematic restitution coefficient $\left(\mathrm{k}_{\mathrm{i}}\right)$. It is evident from this figure that a rock surface inclination has a strong effect on $\mathrm{k}_{\mathrm{i}}$, and a more inclined surface is associated with greater values of $\mathrm{k}_{\mathrm{i}}$ across the whole range of JRC. For example, as the surface inclination increases from 0 to $30^{\circ}$, the $\mathrm{k}_{\mathrm{i}}$ values increase by about $30 \%$. The data in Fig. 6a also suggest no significant influence of JRC on $k_{i}$ for each surface inclination as $k_{i}$ only slightly varies with increasing JRCs.

Figure $6 \mathrm{~b}$ summarises the experimental data in terms of JRC against the rebound angle $(\beta)$. As can be seen in this figure, $\beta$ tends to decrease as the surface inclination increases from $0^{\circ}$ to $30^{\circ}$, with higher rebound angles (about $55-60^{\circ}$ ) observed for the rock surface with no inclination. Relatively high values of standard deviation $\left(\mathrm{SD} \approx 12-26^{\circ}\right)$ were obtained for these 
tests, indicating a high range of the rebound angle produced by the irregular surfaces of S1 and S2. For comparison, a similar type of tests performed by Asteriou et al. (2012) but using a flat rock surface (i.e., no irregularities) resulted in a smaller range of SD from 2-12. This may imply that more irregular surfaces tend to produce larger scatters of data. It is noted that Asteriou and Tsiambaos (2016) pointed out that the shape of falling rocks can also affect the range of SD; that is, rocks with more irregular shapes (such as cubes) tend to produce larger data scatters.

Figure $6 \mathrm{~b}$ also shows that the rock surface irregularities may influence the rebound angle of a falling rock when the surface is not inclined. As can be seen in this figure, the rebound angle tends to decrease from $55-60^{\circ}$ to about $35^{\circ}$ when JRC increases from 8 to 18 , respectively. The effect of JRC on the rebound angle seems to become less pronounced when the rock surface is inclined at $20^{\circ}$ and $30^{\circ}$.

Comparisons with data from previous studies on restitution coefficients given in Table 2 indicate that the results of this work are in agreement with the past research. This table also suggests that compared to the field tests, laboratory experiments can produce normal and tangential restitution coefficients which are greater than one. According to Buzzi et al. (2012), such high values can occur due to the combination of block shape, rotational energy of the falling rock, and impacting angles.

Variations of maximum and average values of normal $\left(\mathrm{k}_{\mathrm{n}}\right)$ and tangential $\left(\mathrm{k}_{\mathrm{t}}\right)$ restitution coefficients in respect to JRC are shown in Figs. 7 and 8. The maximum values of $\mathrm{k}_{\mathrm{n}}$ (Fig. 7a) seem to remain in a narrow area of $0.55-0.60$ across the whole range of JRC for the surface angle of $20^{\circ}$. However, for a steeper inclination $\left(30^{\circ}\right), \mathrm{k}_{\mathrm{n}}$ tends to decrease when the surface becomes more irregular (i.e., very high JRCs), which may be related to the observed decrease 
in rebound angles (Fig. 6b). Figure $7 \mathrm{a}$ also indicates that a steeper surface angle $\left(30^{\circ}\right)$ is associated with higher values of $\mathrm{k}_{\mathrm{n}}$. In contrast, a more gentle surface angle $\left(20^{\circ}\right)$ results in higher values of $k_{t}$ for the whole JRC range (Fig. 7b).

The average values of $k_{n}$ (Fig. 8a) seem to be slightly higher in the middle of JRC range (814), while for the tangential restitution coefficient (Fig. 8b), higher values of $\mathrm{k}_{\mathrm{t}}$ were observed at the low $(\mathrm{JRC} \approx 4)$ and high $(\mathrm{JRC} \approx 18)$ ends of the range. Figure 8b also suggests that $k_{t}$ has a tendency to decrease as JRC (i.e., surface roughness) increases from 2 to 14, which is more pronounced for the steeper surface of $30^{\circ}$. Comparisons between the experimental data from Fig. 8a and Fig. 8b show that the effect of surface angle is more pronounced for the tangential restitution coefficient when the surface inclined at $20^{\circ}$ produced higher values of $\mathrm{k}_{\mathrm{t}}$ across the whole range of JRC.

Relation to field conditions. Considering the ratio between the falling rock (diameter is 30 $\mathrm{mm})$ and the rock surface length $(100 \mathrm{~mm})$ used in this study, the experimental setup can be scaled up to approximately represent field conditions where a falling rock of diameter $1 \mathrm{~m}$ lands on irregular rock surface of about $3.3 \mathrm{~m}$ long. There have been attempts in the literature to account for surface roughness of natural slopes using $\mathrm{MOH}$ (Mean Obstacle Height), a parameter employed by Dorren et al. (2004, 2006) to simulate rock fall phenomena. The value of $\mathrm{MOH}$ is found to increase when the slope surface becomes more irregular. By performing a series of field tests, Dorren et al. (2006) noted the importance of $\mathrm{k}_{\mathrm{t}}$ and $\mathrm{MOH}$ in accurate numerical simulation of rock falls and proposed empirical relationships between these parameters where a higher $\mathrm{MOH}$ results in lower values of $\mathrm{k}_{\mathrm{t}}$. Similar relationship was observed in this study using a small-scaled setup where more irregular surfaces (JRCs from 4-14 in Fig. 8b) resulted in smaller values of $k_{t}$. 


\section{Conclusions}

In this work, a series of laboratory tests were performed to study the effect of surface roughness on the type of rock motion and restitution coefficients. Based on the obtained results, the following conclusions can be drawn:

- The experimental data showed that for more irregular surfaces, the type of motion could become more random, changing from the "bouncing" to "sliding" or "rolling". These results seem to be in agreement with the previous numerical studies, thus providing more experimental evidence to support them.

- The kinematic restitution coefficient does not seem to be affected by changes in the surface roughness; however, the rebound angle tends to decrease as the surface becomes more irregular.

- Compared to the previous studies where the rock surface was assumed flat, this work shows that the surface irregularities may affect the type of rock motion and thus it needs to be considered in rock fall analysis. It is also suggested that the range of standard deviation that is currently used in kinematic analysis should be revisited to account for the larger data scatter caused by surface irregularities.

\section{Acknowledgments}

The authors would like to acknowledge Mr. Thomas Cogan for his invaluable help with laboratory testing. This research did not receive any specific grant from funding agencies in the public, commercial, or not-for-profit sectors.

\section{References}


Asteriou, P., Saroglou, H., and Tsiambaos, G., 2012. Geotechnical and kinematic parameters affecting the coefficients of restitution for rock fall analysis. International Journal of Rock Mechanics and Mining Sciences, 54, 103-113.

Asteriou, P., and Tsiambaos, G., 2016. Empirical model for predicting rockfall trajectory direction. Rock Mechanics and Rock Engineering, 49 (3), 927-941.

Barton, N., and Choubey, V., 1977. The shear strength of rock joints in theory and practice. Rock Mechanics, 10 (1), 1-54.

Buzzi, O., Giacomini, A., and Spadari, M., 2012. Laboratory investigation on high values of restitution coefficients. Rock Mechanics and Rock Engineering, 45 (1), 35-43.

Chau, K.T., Wong, R.H.C., and Wu J.J., 2002. Coefficient of restitution and rotational motions of rock fall impacts. International Journal of Rock Mechanics and Mining Sciences, 39 (1), 69-77.

Dorren, L.K.A., Maier, B., Putters, U.S., and Seijmonsbergen, A.C., 2004. Combining field and modelling techniques to assess rockfall dynamics on a protection forest hillslope in the European Alps. Geomorphology, 57 (3-4), 151-167.

Dorren, L.K.A., Berger, F., and Putters, U.S., 2006. Real-size experiments and 3-D simulation of rockfall on forested and non-forested slopes. Natural Hazards and Earth System Science, 6 (1), 145-53.

Giani, G.P., Giacomini, A., Migliazza, M., and Segalini, A., 2004. Experimental and theoretical studies to improve rock fall analysis and protection work design. Rock Mechanics and Rock Engineering, 37 (5), 369-389. 
Kim, D.H., Gratchev, I., Berends, J., and Balasubramaniam, A., 2015a. Calibration of restitution coefficients using rockfall simulations based on 3D photogrammetry model: a case study. Natural Hazards, 78 (3), 1931-1946.

Kim, D.H., Gratchev, I., and Balasubramaniam, A., 2015b. Back analysis of a natural jointed rock slope based on the photogrammetry method. Landslides, 12 (1), 147-154.

Labiouse, V., and Heidenreich, B., 2009. Half-scale experimental study of rock fall impacts on sandy slopes. Natural Hazards and Earth System Science, 9 (6), 1981-1993.

Pfeiffer, T., and Bowen, T., 1989. Computer simulation of rock falls. Bulletin of the Association of Engineering Geologists, 26 (1), 135-146.

Ritchie, A.M., 1963. The evaluation of rock fall and its control. Stability of rock slopes, Highway Research Record, 1-28.

Spadari, M., Giacomini, A., Buzzi, O., Fityus, S., and Giani G.P., 2012. In situ rock fall testing in New South Wales, Australia. International Journal of Rock Mechanics and Mining Sciences, 49, 84-93.

Wang, I., and Lee, C., 2010. Influence of slope shape and surface roughness on the moving paths of a single rock fall. World Academy of Science, Engineering and Technology, 4 (5), 844-850.

Wu, S.S., 1985. Rock fall evaluation by computer simulation. Geotechnical Engineering Research, Transportation Research Record N1031, 1-5. 
Table 1 . Summary of laboratory data

\begin{tabular}{|c|c|c|c|c|c|c|c|c|c|c|}
\hline \multirow{2}{*}{$\begin{array}{l}\text { Surface } \\
\text { angle }\left(^{\circ}\right)\end{array}$} & \multirow[t]{2}{*}{ JRC } & \multirow[t]{2}{*}{$\begin{array}{l}\text { No. of } \\
\text { tests }\end{array}$} & \multicolumn{2}{|c|}{$\begin{array}{c}\text { Kinematic } \\
\text { restitution } \\
\text { coefficient, } \mathrm{k}_{\mathrm{i}}\end{array}$} & \multicolumn{2}{|c|}{$\begin{array}{l}\text { Normal restitution } \\
\text { coefficient, } \mathrm{k}_{\mathrm{n}}\end{array}$} & \multicolumn{2}{|c|}{$\begin{array}{c}\text { Tangential } \\
\text { restitution } \\
\text { coefficient, } \mathrm{k}_{\mathrm{t}}\end{array}$} & \multicolumn{2}{|c|}{ Rebound angle $\left(^{\circ}\right)$} \\
\hline & & & Mean & SD & Mean & SD & Mean & SD & Mean & SD \\
\hline \multirow{5}{*}{0} & 4 & 13 & 0.39 & 0.12 & - & - & - & - & 56.05 & 26.17 \\
\hline & 8 & 11 & 0.45 & 0.12 & - & - & - & - & 61.53 & 20.44 \\
\hline & 12 & 9 & 0.41 & 0.09 & - & - & - & - & 53.82 & 30.50 \\
\hline & 14 & 8 & 0.33 & 0.04 & - & - & - & - & 55.74 & 26.42 \\
\hline & 18 & 8 & 0.38 & 0.12 & - & - & - & - & 33.85 & 20.53 \\
\hline \multirow{6}{*}{20} & 4 & 14 & 0.51 & 0.09 & 0.33 & 0.10 & 1.10 & 0.46 & 41.48 & 18.90 \\
\hline & 8 & 11 & 0.48 & 0.10 & 0.36 & 0.10 & 0.92 & 0.34 & 48.30 & 16.90 \\
\hline & 12 & 12 & 0.47 & 0.15 & 0.35 & 0.15 & 0.93 & 0.42 & 46.70 & 17.68 \\
\hline & 14 & 11 & 0.48 & 0.12 & 0.36 & 0.16 & 0.91 & 0.30 & 45.97 & 17.22 \\
\hline & 16 & 7 & 0.40 & 0.23 & 0.21 & 0.01 & 0.96 & 0.80 & 42.05 & 26.14 \\
\hline & 18 & 9 & 0.47 & 0.15 & 0.24 & 0.08 & 1.16 & 0.56 & 26.78 & 18.66 \\
\hline \multirow{6}{*}{30} & 4 & 21 & 0.55 & 0.13 & 0.27 & 0.11 & 0.97 & 0.30 & 27.92 & 14.62 \\
\hline & 8 & 17 & 0.55 & 0.11 & 0.37 & 0.18 & 0.80 & 0.34 & 39.46 & 21.15 \\
\hline & 12 & 14 & 0.52 & 0.08 & 0.39 & 0.12 & 0.75 & 0.20 & 37.76 & 12.58 \\
\hline & 14 & 11 & 0.51 & 0.12 & 0.39 & 0.11 & 0.70 & 0.34 & 46.50 & 16.78 \\
\hline & 16 & 8 & 0.57 & 0.09 & 0.32 & 0.17 & 0.94 & 0.35 & 31.42 & 21.49 \\
\hline & 18 & 10 & 0.56 & 0.16 & 0.34 & 0.20 & 0.85 & 0.48 & 29.82 & 26.50 \\
\hline
\end{tabular}

Note: SD- standard deviation, JRC - joint roughness coefficient.

Table 2. Comparisons with previous studies.

\begin{tabular}{|l|l|c|c|c|}
\hline \multirow{2}{*}{ Experimental studies } & $\begin{array}{c}\text { Coefficient } \\
\text { of } \\
\text { restitution }\end{array}$ & $\begin{array}{c}\text { Normal } \\
\text { restitution } \\
\text { coefficient }\end{array}$ & $\begin{array}{c}\text { Tangential } \\
\text { restitution } \\
\text { coefficient }\end{array}$ \\
\hline \multirow{3}{*}{$\begin{array}{l}\text { In-situ } \\
\text { investigations }\end{array}$} & Giani et al. (2004) & - & 0.48 & 0.79 \\
\cline { 2 - 5 } & Dorren et al. (2006) & - & $0.11-0.41$ & $0.5-0.95$ \\
\cline { 2 - 5 } & Spadari et al. (2012) & - & $0.38-1.98$ & $0.37-0.96$ \\
\hline \multirow{3}{*}{$\begin{array}{l}\text { Laboratory } \\
\text { tests }\end{array}$} & Wu (1985) & - & $0.20-0.80$ & $0.60-0.90$ \\
\cline { 2 - 5 } & Chau et al. (2002) & $0.41-1.00$ & $0.35-0.60$ & $0.60-0.90$ \\
\cline { 2 - 5 } & Asteriou et al. (2012) & $0.36-0.91$ & $0.25-0.88$ & $0.68-1.63$ \\
\cline { 2 - 5 } & Buzzi et al. (2012) & - & $0.30-1.80$ & $0.15-1.25$ \\
\cline { 2 - 5 } & Asteriou and Tsiambaos & $0.19-0.84$ & $0.02-0.70$ & $0.44-1.16$ \\
\hline This study & (2016) & $0.30-0.72$ & $0.21-0.67$ & $0.40-1.80$ \\
\hline
\end{tabular}


Figure 1. An experimental setup.

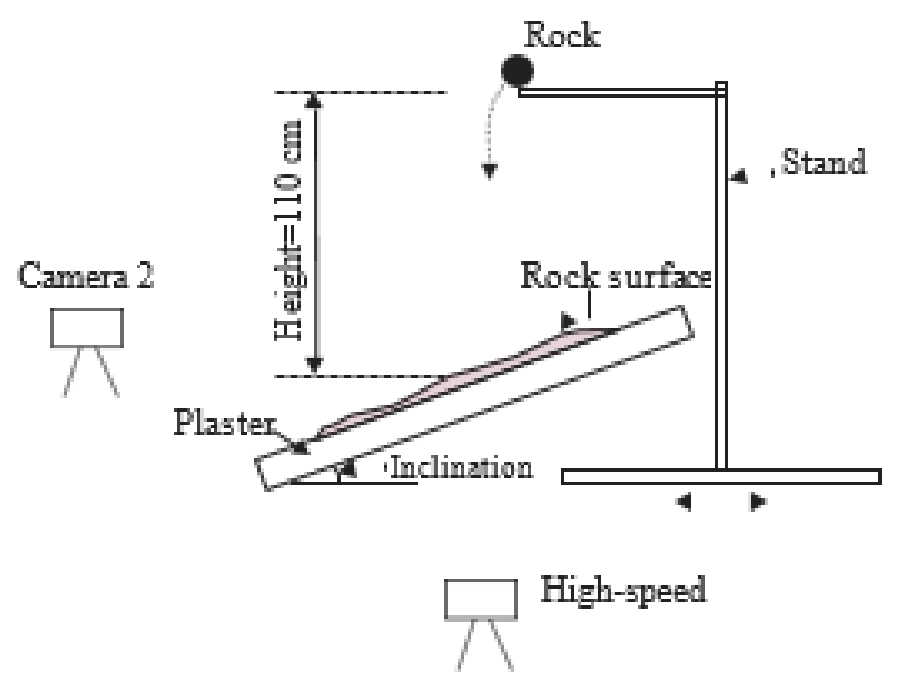

Figure 2. Rock surfaces: (a) S1 and (b) S2.

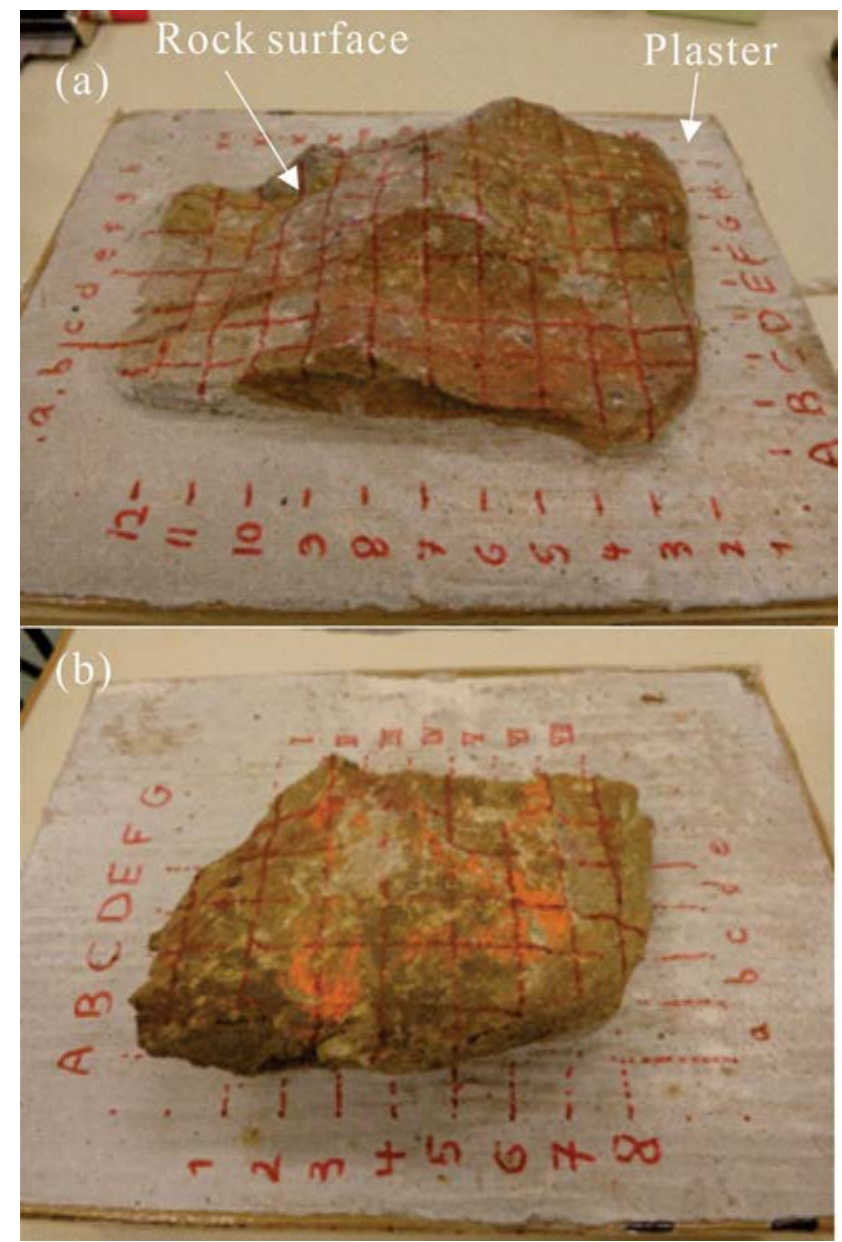


Figure 3. A grid pattern of S1 (a) and S2 (b).
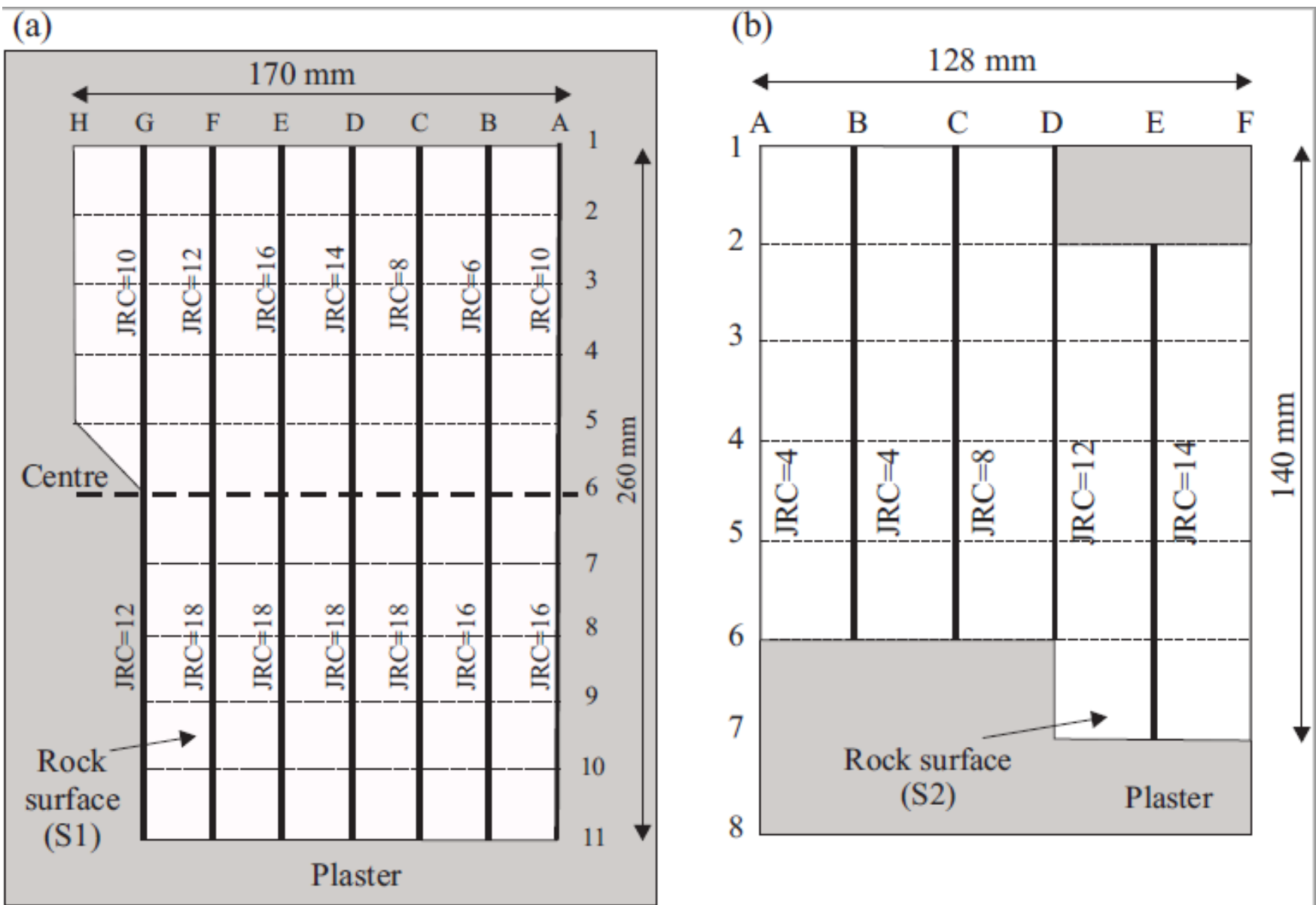
Figure 4. Rock's trajectory during testing (a), and the geometry of the problem (b).

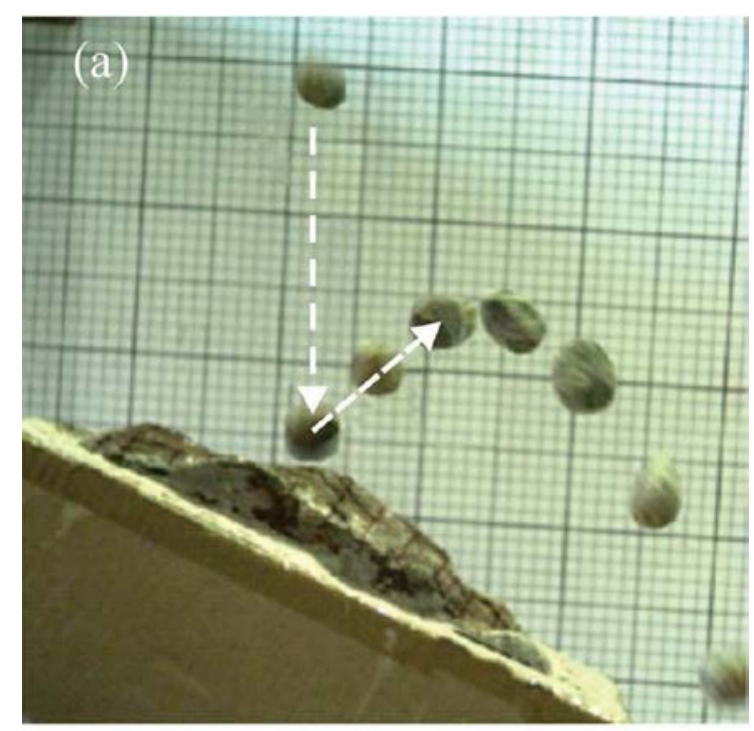

(b)

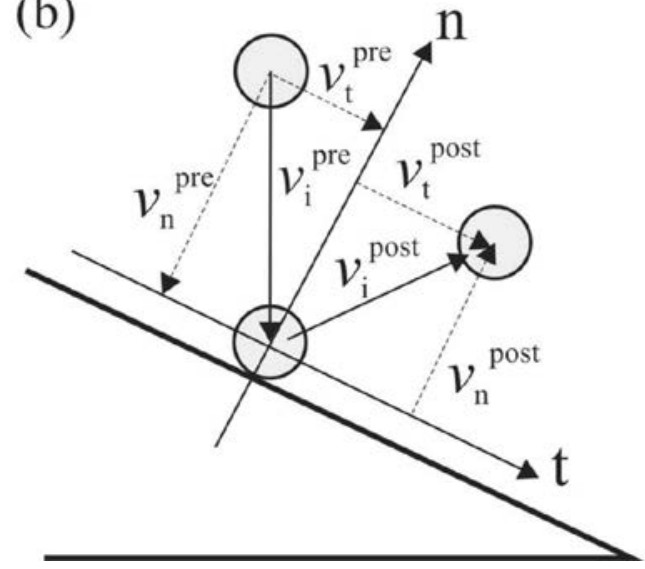


Figure 5. Experimental data showing the location of impact points for a series of tests with S1 inclined at $20^{\circ}$.

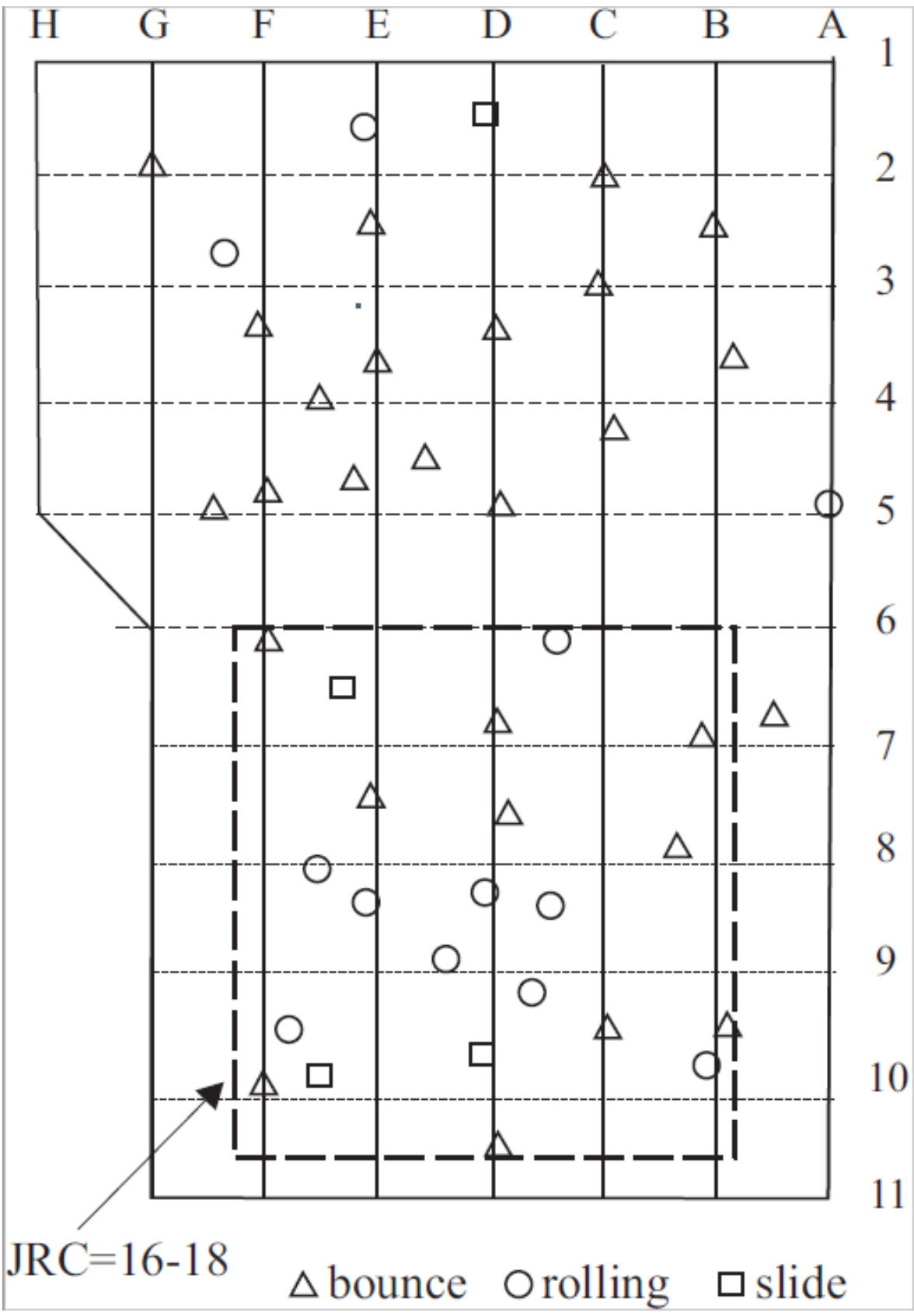


Figure 6. Results of laboratory tests plotted as JRC against (a) the kinematic restitution coefficient, and (b) the rebound angle.
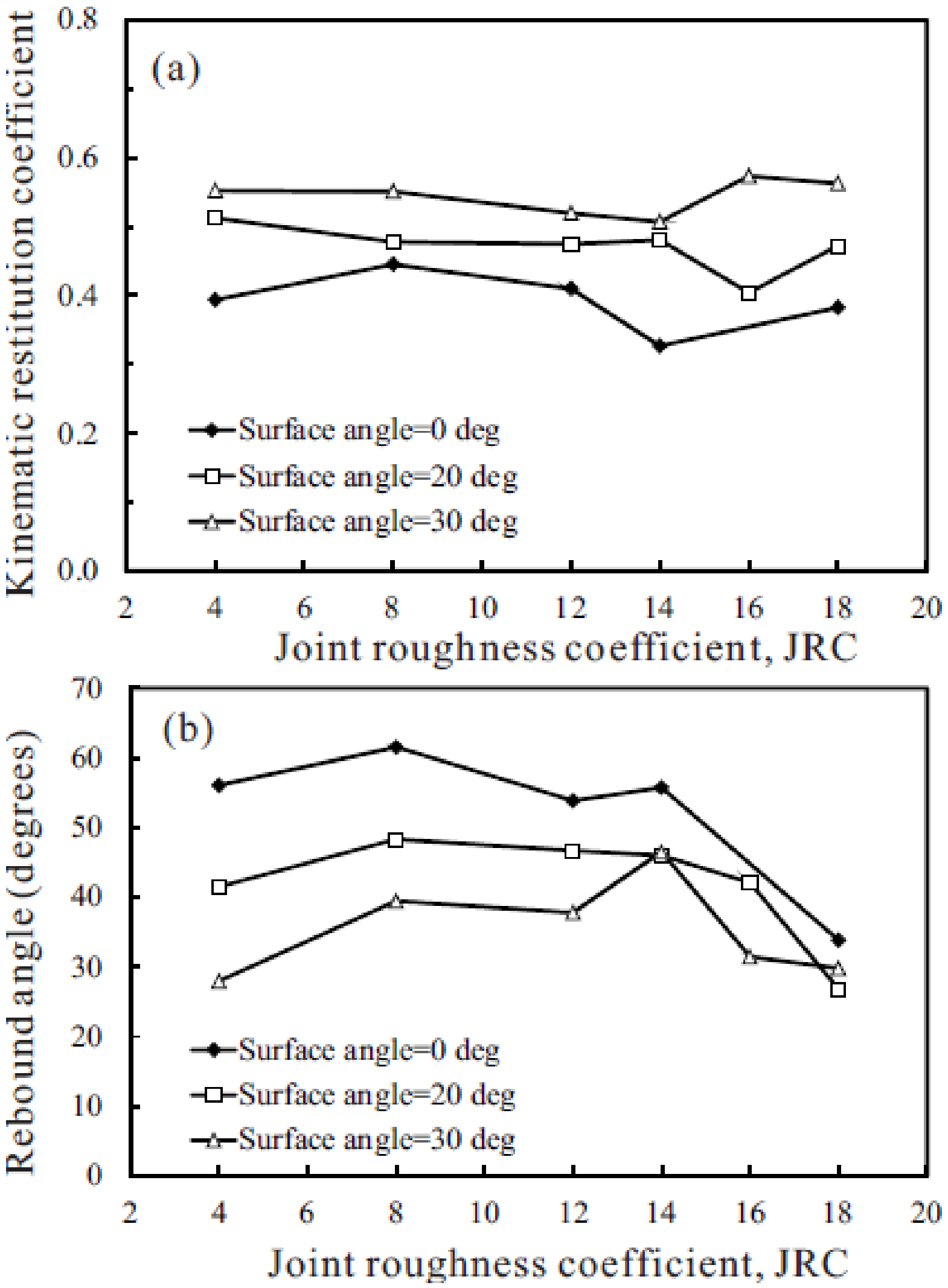
Figure 7. Results of laboratory tests plotted as JRC against the maximum values of (a) normal restitution coefficient, and (b) tangential restitution coefficient.
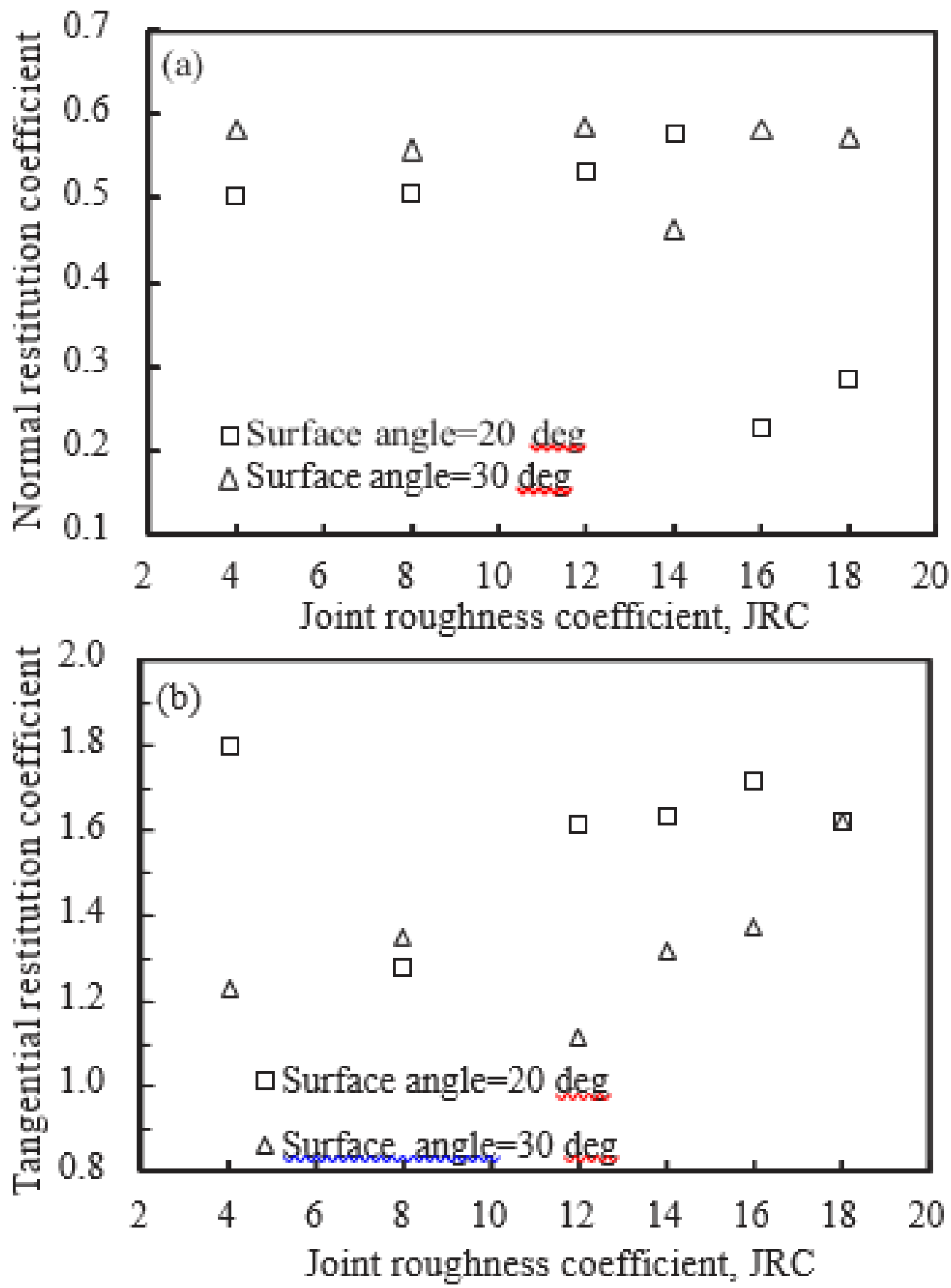
Figure 8. Results of laboratory tests plotted as JRC against the mean values of (a) normal restitution coefficient, and (b) tangential restitution coefficient.
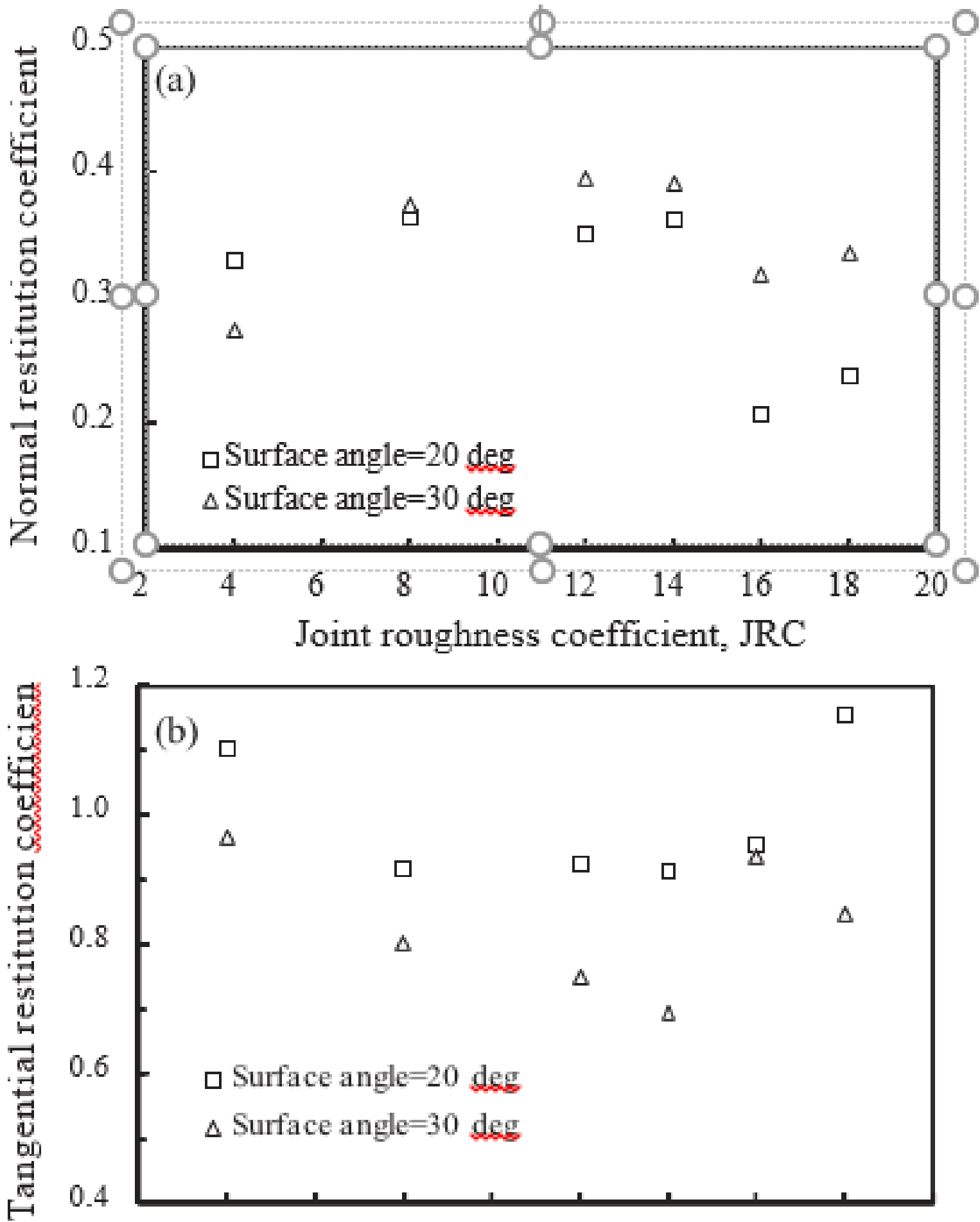